\title{
Using technology-enabled social prescriptions to disrupt healthcare
}

Short title: Technology-enabled social prescriptions

Sven Jungmann ${ }^{1}$, Pritesh Mistry², Tim Conibear ${ }^{3}$, Muir Gray $^{4}$, Anant Jani $^{4^{*}}$

1. FACTOR10 GMbH, Berlin, Germany

2. Royal College of General Practitioners, London, UK

3. Waves for Change, Cape Town, South Africa

4. University of Oxford, Value Based Healthcare Programme - Dept of Primary Care Radcliffe Primary Care Building, Radcliffe Observatory Quarter, Woodstock Rd, Oxford, Oxfordshire, UK OX2 6GG

\section{*Correspondences should be addressed to anant.jani@phc.ox.ac.uk}

Declaration of conflicting interests: The Author(s) declare(s) that there are no conflicts of interest.

Funding: This research received no specific grant from any funding agency in the public, commercial, or not-for-profit sectors.

Guarantor: Anant Jani is the Guarantor for the article.

Contributorship statement: Sven Jungmann and Anant Jani were involved in the design and writing of the mansucript; Pritesh Mistry, Tim Conibear and Muir Gray were involved in writing the manuscript. 
Healthcare systems are facing increasing need and demand because of aging populations, increasing chronic disease and multimorbidity, and new therapeutics and diagnostics being brought to market. These factors, when combined, require unsustainable levels of funding. ${ }^{1}$ We must also acknowledge that a large proportion of chronic diseases that plague healthcare systems are preventable or can be brought into remission through lifestyle interventions and that $70 \%$ of health outcomes are determined by social factors that remain mostly unaddressed in healthcare systems predicated on the biomedical model. ${ }^{2}$

There have been various attempts to look outside the biomedical box since the birth of social medicine in the $19^{\text {th }}$ century but none of the approaches has been able to challenge the dominance of the biomedical model. More recently, however, the rise of social prescriptions across European countries gives hope that there are non-biomedical means we can use to improve patient and population outcomes while optimising resource utilisation. Social prescriptions provide a way to connect individuals to sources of support within their community to address social determinants of health and encourage self-care for a variety of physical and mental health conditions. ${ }^{2}$

\section{Tech-enabled Social Prescribing: A "Disruption from Below”}

The economic concept of "disruption from below" describes a situation in which an organisation provides a cheaper solution to a problem that is less profitable for the incumbent. But more significant is that the new solution is better in some key ways that are important to the user. Typically, the margins of the new solutions are too low for the existing players, who prefer to stay 
with their more profitable solution rather than cannibalising their own market. Eventually, this novel solution becomes increasingly better and takes a larger share of the market and/or taps into a user base that did not use the services previously because they were too expensive.

The rise of the desktop computer versus the established mainframe computers is one example of such a disruption dynamic. The desktop computer was easier to use but it had fewer capabilities than a mainframe computer. The established mainframe manufacturers ignored the cheaper desktop computers only to find they improved quickly adding more functionality and they soon overtook the mainframes relegating them to a footnote in history. In health care, the pharmaceutical industry currently faces the "better than the beatles" problem: unlike a new song, novelty has no intrinsic value in pharmaceuticals. ${ }^{3}$ New pharmaceuticals must significantly outperform the gold standard to justify the high prices charged to recoup their development costs, which typically lie in the billions.

Social prescriptions have the potential to affect our health at much lower cost and fewer side effects than most medicines. Social prescriptions are poised to become a key disruptive force in $21^{\text {st }}$ century healthcare because they can: a) be personalised and be highly adaptable to individual needs/expectations, which is currently largely impossible for most pharmaceuticals; b) effectively address many health and care issues associated with lifestyle-related chronic conditions; and c) address non-biomedical issues related to social determinants of health. 
But there are several strategic, operational and tactical barriers that we must actively overcome to fully realise the disruptive potential of social prescriptions. The hope is that digital technologies will make it possible to scale social prescriptions because: a) digital technologies make it easier and cheaper to obtain relevant information on individual patients, providers and the system; $b$ ) they can increase flexibility outside of the traditional place-based care approach (e.g. online remote monitoring of vulnerable people and flagging changes in conditions that might require medication adjustments); and c) they provide $24 / 7$ interaction and automated functionality with the ability to provide nudges to patients and for the user to deliver frequent feedback as needed.

In this manuscript, we argue that in order for social prescriptions to achieve their disruptive potential, they need to be informed by technological and lifestyle trends that influence our daily behaviour, particularly those that would allow social prescriptions to blend into what feels normal to patients' regular lives.

\section{Tech-enabled social prescriptions as a living service}

"Living Services" are enabled by digitally-connected intelligence and are defined as:

sophisticated, contextually-aware digital services designed to anticipate and respond to your needs. They react in real-time to changes in the environment and patterns of behavior, in ways that will transform how we live, work and play. 
A necessary precondition of living services is a combination of ubiquitously available sensors (such as wearables, nearables, and ingestibles), connected devices, user interfaces, the cloud, and network connectivity combined with data (including patient reported outcome measures), and analytics. Advances in behaviour change science are also important to help translate the insights from these technologies into healthier behaviour. From a systems perspective, this could give rise to "Learning Health Care Systems" ${ }^{4}$ which could utilise wearable sensors and patient reported outcome data to enable the continuous collection of dynamic types of data required for analyses to elucidate microtemporal processes relevant to health-promoting behaviors. ${ }^{5}$ If this data is linked to personal health profiles that inform case-mix-calculations and outcome measurements, prescribers can receive tailored prescribing recommendations, researchers can access data and patients can access predictive models that can help them compare themselves against their reference population and receive credible feedback on the health benefits incurred as a consequence of their adherence to different social prescriptions. This also constitutes a shift from intuitive and empirical to truly precise medicine. ${ }^{6}$

\section{Tech-enabled social prescriptions in practice}

There are hundreds of technologies that could facilitate the design and delivery of social prescriptions. Table 1 lists several digital technologies that each can make the delivery of certain aspects of care cheaper for the system and more convenient to patients (e.g. because they can access them at anytime and anywhere). Other data sources could be obtained from spending data and sensors in home appliances (e.g. bed or refrigerator) to obtain an even more complete insight on an individual's lifestyle. Taken together, these technologies promise to give individual 
patients precise behavioural recommendations that are tailored exactly for their needs and deliver reasonably predictable therapeutic benefits. Higher personal relevance could compel more users to adopt a specific regimen versus population data derived from large randomised controlled trials with strict inclusion and exclusion criteria that might not apply to the individual user. From a systems perspective, these technologies could result in improved efficiency, economic benefits and reduced human exertions.

\begin{tabular}{|c|c|c|}
\hline TECHNOLOGY & WHAT COULD BE DELIVERED & POTENTIAL BENEFITS \\
\hline Telemedicine & $\begin{array}{l}\text { - } \text { Prescribing } \\
\text { - } \text { Monitoring } \\
\text { - } \text { Coaching }\end{array}$ & $\begin{array}{l}\text { - Patient does not need to } \\
\text { travel } \\
\text { - Can be delivered outside } \\
\text { of office hours } \\
\text { - Underserved regions get } \\
\text { access } \\
\text { - Doctors free capacity and } \\
\text { increase their } \\
\text { productivity }\end{array}$ \\
\hline $\begin{array}{l}\text { Smartphone apps (excluding } \\
\text { software interventions like } \\
\text { digital therapeutics) }\end{array}$ & $\begin{array}{l}\text { - } \text { General information } \\
\text { - Personal information } \\
\text { - Patient Reported } \\
\text { Outcome Measures }\end{array}$ & $\begin{array}{l}\text { Relevant information } \\
\text { including alerts can be } \\
\text { delivered just in time } \\
\text { without the constant } \\
\text { need for a health-care } \\
\text { provider } \\
\text { - User-friendly } \\
\text { visualisation and } \\
\text { explanations using multi- } \\
\text { media can reduce health } \\
\text { literacy problems, } \\
\text { reducing the amount of } \\
\text { time required from } \\
\text { health care professionals } \\
\text { to educate patients }\end{array}$ \\
\hline Sensors and wearables & $\begin{array}{l}\text { - } \text { Remote monitoring } \\
\text { - Behavioural data }\end{array}$ & $\begin{array}{l}\text { - Passively obtain more } \\
\text { complete picture }\end{array}$ \\
\hline
\end{tabular}




\begin{tabular}{|c|c|c|}
\hline & $\begin{array}{l}\text { - Personal health data, e.g. } \\
\text { EKG, Bodyweight, } \\
\text { Temperature, etc. } \\
\text { - Environmental data (air } \\
\text { pollution, temperature, } \\
\text { etc.) }\end{array}$ & $\begin{array}{l}\text { through real world } \\
\text { evidence (i.e. no manual } \\
\text { labor needed by health } \\
\text { care professionals) } \\
\text { Make social prescribing } \\
\text { safer in the absence of } \\
\text { expert staff (e.g. notify } \\
\text { when cardiac } \\
\text { abnormalities are } \\
\text { recognised during } \\
\text { exercise) }\end{array}$ \\
\hline $\begin{array}{l}\text { Virtual and augmented } \\
\text { reality }\end{array}$ & $\begin{array}{l}\text { - } \quad \text { Content delivery } \\
\text { - Ambience creation }\end{array}$ & $\begin{array}{l}\text { - Provide options for self- } \\
\text { treatment (e.g. against } \\
\text { phobias }^{7} \text { or for } \\
\text { relaxation }^{8} \text { ) }\end{array}$ \\
\hline $\begin{array}{l}\text { Interventional and } \\
\text { rehabilitative robotics }\end{array}$ & - Enhancing mobility & $\begin{array}{l}\text { - Improve waiting times } \\
\text { overcome staff } \\
\text { shortages by enabling 1- } \\
\text { to-many interventions } \\
\text { with clinical oversight } \\
\text { Obtaining automated } \\
\text { help to gradually regain } \\
\text { mobility }\end{array}$ \\
\hline
\end{tabular}

Table 1: How digital technologies can deliver certain aspects of care relevant to social prescribing.

As technologies improve, social prescriptions could have a stronger impact, particularly for chronic diseases that are driven by lifestyle issues and comprise a significant burden of disease in most countries. Tech-enabled social prescriptions could be made accessible at scale and can deliver more precise and faster adaptable interventions compared with pharmaceuticals, where precision medicine delivered via pharmacogenomics is still very expensive with a significant delay before novel drugs are available on the market. 
Health and care's shift towards tech-enabled social prescriptions is already happening at large and small scales. Platforms like Elemental ${ }^{9}$ focus on coordination of logistics related specifically to social prescribing, while platforms like Intelligent Health ${ }^{10}$ aim to create communities where individuals are connected with local services aimed at improving their health and wellbeing. The Royal College of General Practitioners is also in the pilot stages of a project to explore how Internet of Things could be used to support social prescriptions. ${ }^{11}$ At a more global scale, large technology players like Apple are investing heavily into technology aimed at improving health, as evidenced by the recent FDA approval of the newest version of the Apple watch as a medical device $^{12}$; and Haven, the joint initiative between Amazon, JP Morgan and Berkshire Hathaway aims to leverage "the power of data and technology to drive better incentives, a better patient experience, and a better system" for its employees. ${ }^{13}$

Further to this, as with other disruptive technologies, tech-enabled social prescriptions have the potential to deliver services to those who never had access to them previously. This is particularly important in resource poor settings where tech-enabled social prescriptions could facilitate access to healthcare and also focus on lifestyle interventions to keep people healthy, rather than putting them at risk of developing preventable chronic diseases, as has happened in Western countries. One such example of this is Waves for Change (W4C), a South African NGO which provides community-led physical activity programmes to disadvantaged youth that have been proven to prevent several physical and mental health challenges. W4C has recently launched a platform called 'Coach Assist', which automates the recruitment, payment and tracking of 
community based-volunteers who launch activity-based community groups and receive payments for each individual engaged in their activities. ${ }^{14}$

\section{Scaling tech-enabled social prescriptions}

To enable the health and care system to have functional social prescribing which is both sustainable and effective will require patients and health and care professionals to co-develop and be trained in using technology that removes barriers, manages huge quantities of data and supports all stakeholders to facilitate proactive management of patient care to reduce workload on the system and help the person be in control of their health.

\section{$\underline{\text { Removing barriers }}$}

At its core, social prescribing supports the person to identify their personal goals and facilitates the use of community activities to meet these goals. GPs, link workers, allied healthcare professionals and community providers need to be able to share information and work as a team to help each person, which means information needs to be captured and shared effectively across organisations requiring improved standards and APIs for data sharing that facilitates ethical interoperability, which ensures patient safety and safeguarding of vulnerable people.

\section{Managing data}

Wearables and sensors can give information and insights that previously were not possible to collect. Through improved information flows and multiple measures of impact not only is it possible to capture the value of social prescribing but unintended consequences can also be 
monitored and mitigated through quality improvement approaches. But the active use of wearables and sensors means there will be a very high density of information flowing into systems, which will require effective and efficient data storage as well as facilitative tools to interpret the data and make it meaningful for all stakeholders.

\section{Supporting stakeholders}

Each member of the care team is interested in knowing the impact of the social prescribing through different lenses so capturing information and presenting it to the relevant member of the team in the right way at the right time is essential. Stakeholders will need up to date information on what is available in the community, if patients are engaging with the intervention and whether it has been useful for them. Related to this is the transparency of the quality, evaluation and impact of digital tools which in turn will help build trust.

\section{Let the health and care disruption begin!}

To advance the use of social prescriptions we need to incorporate digital tools and learn from other industries that are already deeply engaged with the everyday lives of their users. Social prescribing supported with technology has the potential to personalise care, bring the person in control of their health and address social determinants of health. While we must continue providing evidence of effectiveness and safety and address novel aspects of safety around data and privacy protection, a bigger mindset shift will be needed to ensure that technology-enabled social prescriptions should also be driven by good user experience and this will require that all of the players in the health and care ecosystem move beyond their existing siloes and adopt a more 
collaborative approach that sees seamless interfaces, a task particularly suitable to digital tools. As FJORD puts it, we live in the era of Liquid Expectations:

When consumers engage with a brand today, such as an airline or a bank, they compare their experience not only with other airlines or banks but also with any service company, such as ridesharing providers. Take the seamless and largely invisible payment systems these providers offer. Now consumers want payment experiences like this in every industry, consciously or subconsciously. ${ }^{15}$

\section{References}

1. Watson J, Salisbury C, Jani A, et al. Better value primary care is needed now more than ever. BMJ. 2017 Nov 10; 359:j4944.

2. Jani A and Gray M. Making social prescriptions mainstream. JRSM. 2019 (in press).

3. Scannell JW, Blanckley A, Boldon $\mathrm{H}$ and Warrington B. Diagnosing the decline in pharmaceutical R\&D efficiency. Nat Rev Drug Discov. 2012 Mar; 11(3):191-200.

4. Learning Healthcare Project. The potential of learning healthcare systems [Internet]. [cited 2019 May 14]. Available from: www.learninghealthcareproject.org/LHS Report 2015.pdf.

5. Dunton GF. Sustaining Health-Protective Behaviors Such as Physical Activity and Healthy Eating. JAMA. 2018 Aug; 320(7):639-640.

6. Christensen C, Grossman J and Hwang J. The Innovator's Prescription: A disruptive solution for healthcare. 2009. McGraw-Hill Education: New York. 
7. Donker T, Cornelisz I, van Klaveren C, et al. Effectiveness of Self-guided App-Based Virtual Reality Cognitive Behavior Therapy for Acrophobia. JAMA Psychiatry. 2019 Mar; doi:10.1001/jamapsychiatry.2019.0219.

8. IEEE Xplore Digital Library. Promoting relaxation using virtual reality, olfactory interfaces and wearable EEG [Internet]. [cited 2019 May 14]. Available from: https://ieeexplore.ieee.org/abstract/document/8329668.

9. Elemental. Elemental the social prescribing people [Internet]. [cited 2019 May 14]. Available from: https://elementalsoftware.co/.

10. Intelligent Health. Building active communities [Internet]. [cited 2019 May 14]. Available from: http://www.intelligenthealth.co.uk/.

11. Pitch-In: Connecting Capabilities for the Internet of Things. Understanding how loTenabled social prescriptions can deliver value in healthcare systems [Internet]. [cited 2019 May 14]. Available from: http://pitch-in.ac.uk/projects/iot-social-prescriptionshealthcare/.

12. Forbes. Apple Watch 4 Is Now An FDA Class 2 Medical Device: Detects Falls, Irregular Heart Rhythm [Internet]. [cited 2019 May 14]. Available from: https://www.forbes.com/sites/jeanbaptiste/2018/09/14/apple-watch-4-is-now-an-fdaclass-2-medical-device-detects-falls-irregular-heart-rhythm/\#6688f0052071.

13. Haven Healthcare. Vision [Internet]. [cited 2019 May 14]. Available from: https://havenhealthcare.com/vision. 
14. Baseline Software. Coach assist platform: Attendance monitoring software [Internet]. [cited 2019 May 14]. Available from: http://baselinesoftware.co.za/our-work/waves-forchange-coach-assist.

15. Business Wire. Ground-Breaking Report From Accenture Interactive Finds Internet of Things Driving New Era of "Living Services" [Internet]. [cited 2019 May 14]. Available from: https://www.businesswire.com/news/home/20150615005167/en/GroundBreaking-Report-Accenture-Interactive-Finds-Internet-Things. 